\title{
Lipoteichoic Acid Isolated from Lactobacillus plantarum Maintains Inflammatory Homeostasis through Regulation of Th1- and Th2- Induced Cytokines
}

\author{
Ji Eun $\mathrm{Ahn}^{1}$, Hangeun $\mathrm{Kim}^{2 *}$, and Dae Kyun Chung ${ }^{1,2 *}$ \\ ${ }^{1}$ Graduate School of Biotechnology, Kyung Hee University, Yongin 17104, Republic of Korea \\ ${ }^{2}$ Skin Biotechnology Center, Kyung Hee University, Yongin 17104, Republic of Korea
}

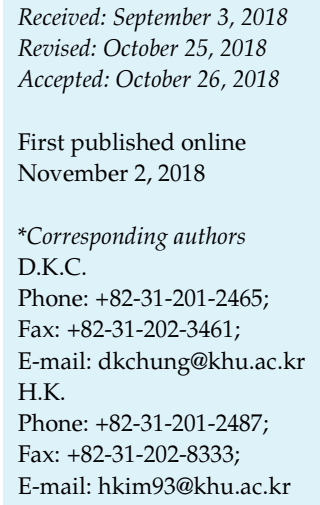

Lipoteichoic acid isolated from Lactobacillus plantarum K8 (pLTA) alleviates lipopolysaccharide (LPS)-induced excessive inflammation through inhibition of TNF- $\alpha$ and interleukin (IL)-6. In addition, pLTA increases the survival rate of mice in a septic shock model. In the current study, we have found that pLTA contributes to homeostasis through regulation of pro- and anti-inflammatory cytokine production. In detail, pLTA decreased the production of IL-10 by phorbol-12-myristate-13-acetate (PMA)-differentiated THP-1 cells stimulated with prostaglandin E2 (PGE-2) and LPS. However, TNF- $\alpha$ production which was inhibited by PGE-2+LPS increased by pLTA treatment. The regulatory effects of IL-10 and TNF- $\alpha$ induced by PGE-2 and LPS in PMA-differentiated THP-1 cells were mediated by pLTA, but not by other LTAs isolated from either Staphylococcus aureus (aLTA) or L. sakei (sLTA). Further studies revealed that pLTA-mediated IL-10 inhibition and TNF- $\alpha$ induction in PGE-2+LPS-stimulated PMAdifferentiated THP-1 cells were mediated by dephosphorylation of p38 and phosphorylation of c-Jun N-terminal kinase (JNK), respectively. Reduction of pLTA-mediated IL-10 inhibited the metastasis of breast cancer cells (MDA-MB-231), which was induced by IL-10 or conditioned media prepared from PGE-2+LPS-stimulated PMA-differentiated THP-1 cells. Taken together, our data suggest that pLTA contributes to inflammatory homeostasis through induction of repressed pro-inflammatory cytokines as well as inhibition of excessive antiinflammatory cytokines.

Keywords: Lipoteichoic acid, anti-inflammation, homeostasis, interleukin-10, tumor necrosis factor-alpha, metastasis of breast cancer

\section{Introduction}

Lipoteichoic acid (LTA) is a cell wall component of Gram-positive bacteria that contributes to inflammatory responses through induction of pro-inflammatory cytokines and affects bacterial growth. The structure of glycopolymer, which extends from the cytoplasmic membrane to the extracellular space, varies between different species of Gram-positive bacteria [1]. Structural and functional studies of LTA have focused on pathogenic bacteria because LTA is a key stimulator in inflammatory and infectious diseases. However, unlike LTAs isolated from pathogenic bacteria, some LTAs from probiotics alleviate excessive inflammatory responses via induction of tolerance against pathogenic ligands. In previous studies, we have shown that LTA isolated from Lactobacillus plantarum (pLTA) inhibits TNF- $\alpha$ production induced by lipopolysaccharide (LPS) or LTA isolated from Staphylococcus aureus (aLTA), which resulted in an increased survival rate in a septic shock mouse model $[2,3]$. pLTA also has the potential ability to prevent and treat skin photo-aging via down-regulation of UV-induced MMP-1 expression and up-regulation of type I procollagen [4]. Similarly, it inhibits melanogenesis in B16F10 mouse melanoma cells, which suggests that pLTA has therapeutic 
potential for hyperpigmentation disorders [5]. Plateletactivating factor receptor (PAFR) plays an important role in bacterial infection and inflammation. Through an in vitro study using THP-1 cells, we showed that pLTA inhibits PAFR expression induced by pathogenic ligands, which results in anti-inflammatory effects [6]. Thereby, we have shown that pLTA has potential for alleviation of excessive inflammation. However, the effect of pLTA on regulation of anti-inflammatory responses has not yet been determined.

Inflammation is a complex biological response of the body, caused by harmful stimuli, such as infected pathogens, damaged cells, or irritants. It is also a protective response involving immune cells, blood vessels, and molecular mediators. Inflammation eliminates the infected pathogens, removes necrotic cells, and clears damaged tissues. Although inflammation is an essential immune reaction, abnormal inflammation causes inflammatory disorders [7]. In particular, chronic inflammation is a critical factor in the pathogenesis of many inflammatory disease states, including cancer, degenerative joint diseases, diabetes, cardiovascular disease, and neurodegenerative diseases. Non-steroidal anti-inflammatory drugs are used to alleviate inflammation, although these drugs are associated with severe side effects. Thus, anti-inflammation is necessary to regulate abnormal inflammation. The term "anti-inflammatory" refers to the property of a material or treatment to reduce inflammation. Interleukin (IL)-10, a representative anti-inflammatory cytokine, inhibits production of pro-inflammatory mediators such as cytokines and chemokines, which results in inactivation of $\mathrm{T}$ cells and macrophages [8-10]. IL-10 is reported to be highly induced in metastatic cancer cells and in the serum of breast cancer patients [11,12]. Thus, inhibition of IL-10 may alleviate IL-10-induced disease as well as anti-inflammatory response. In the current study, we demonstrated that pLTA inhibited IL-10 production and increased TNF- $\alpha$ production in phorbol-12-myristate13-acetate (PMA)-differentiated THP-1 macrophages and alleviated breast cancer cell metastasis. Our data suggest that pLTA regulates both Th1- and Th2-induced cytokines, which contributes to homeostasis of the immune system.

\section{Materials and Methods}

\section{Cell Culture}

THP-1 and MDA-MB-231 cells were maintained in Roswell Park Memorial Institute (RPMI)-1640 medium or Dulbecco's Modified Eagle's Medium (DMEM) (Welgene, Korea) with 10\% heat-inactivated and filtered $(0.45 \mu \mathrm{m}$ syringe filter; Sartorius,
Göttingen, Germany) fetal bovine serum (FBS, Welgene), penicillin $(100 \mathrm{U} / \mathrm{ml})$, and streptomycin $(100 \mu \mathrm{g} / \mathrm{ml})$ in $5 \% \mathrm{CO}_{2}$ at $37^{\circ} \mathrm{C}$. THP-1 cells were plated in 24-well plates and differentiated to macrophages using $100 \mathrm{ng} / \mathrm{ml}$ PMA for 3 days. The differentiation of monocytes to macrophages was confirmed by differentiation markers such as chemokine receptor 2 (CCR2).

\section{Preparation of LTA and Endotoxin Test}

L. plantarum K8 was cultured in 8 L MRS broth (HiMedia Laboratories, India) and incubated for $18 \mathrm{~h}$ at $37^{\circ} \mathrm{C}$. After bacterial cultivation, LTA isolation was performed as previously described [2]. The purity of pLTA was determined by measuring endotoxin content using a ToxinSensor Chromogenic LAL Endotoxin Assay Kit (GenScript, USA).

\section{Cell Proliferation Assay}

PMA-derived macrophages were seeded in 96-well plates and then treated with prostaglandin E2 (PGE-2) and LPS $(100 \mu \mathrm{g} / \mathrm{ml})$. The proliferation activity of PMA-derived macrophages was measured using EZ-cytox Cell Viability Assay Kit (Innotech, Korea) following the manufacturer's instructions. Color changes were detected with a microplate reader (Eppendorf BioPhotometer) at a wavelength of $450 \mathrm{~nm}$.

\section{Real-Time PCR}

Total RNA was isolated using Trizol reagent (Invitrogen, USA). cDNA was synthesized using an Improm-II reverse transcription system (Promega, USA) from isolated RNA. To quantify CD36 and CCR2 mRNA, real-time PCR amplification was conducted using a CFX Connect Real-Time PCR Detection System (Bio-Rad, USA), and the PCR products were detected with SYBR Premix Ex Taq II (TaKaRa, Otsu, Japan). The following sequences were used for forward and reverse primer pairs: $5^{\prime}$-GCCTCTCCAGTTGAA AACCC-3' and 5'-TCCCTTCTTTGCATTTGCTG-3' for CD36, 5'TACCAACGAGAGCGTGAAG-3' and 5'-GTAGAGCGGAGGCAG GAGTT-3' for CCR2, 5'-AAGGTCGGAGTCAACGGATT-3' and 5'-GCAGTGAGGGTCTCTCTCCT-3' for GAPDH. The expression of mRNA was normalized to that of glyceraldehyde-3-phosphate dehydrogenase (GAPDH) or $\beta$-actin.

\section{ELISA}

Culture supernatants were collected from THP-1 cells and PMA-derived macrophages after stimulation with PGE-2, LPS, and pLTA. To block the signaling pathways, NF-кB (Cat\# 481406), ERK (Cat\# 328006), JNK (Cat\# 420119), and p38 (Cat\# 559389) inhibitors (MERCK, Darmstadt, Germany) were pretreated for 30 min prior to stimulation with ligands. To perform a standard sandwich ELISA in 96-well immune plates, human IL-10 and TNF- $\alpha$ were captured with antibodies (purchased from R\&D Systems, USA) and incubated at room temperature (RT) overnight. Plates were blocked with blocking buffer ( $5 \%$ sucrose, $1 \%$ BSA, $0.05 \%$ NaN3 in PBS) for $2 \mathrm{~h}$, and supernatants were added to each well. After incubation, the plates were washed with 
washing buffer (0.05\% Tween 20 in PBS), and detection antibodies (R\&D Systems) were added and incubated for $2 \mathrm{~h}$. After washing, HRP was added and incubated for $20 \mathrm{~min}$. After washing, substrate reagents were added, and the results were measured at wavelengths of $450 \mathrm{~nm} / 550 \mathrm{~nm}$.

\section{Western Blot Assay}

After PGE-2- and LPS-treated, PMA-derived macrophages were lysed with $2 \times$ Laemmli sample buffer, samples were boiled at $100^{\circ} \mathrm{C}$ for $5 \mathrm{~min}$. Proteins were separated using $12 \%$ sodium dodecyl sulfate-polyacrylamide electrophoresis gel and transferred onto a polyvinylidene fluoride membrane. Membranes were then incubated with blocking buffer $(5 \%$ BSA, $20 \mathrm{mM}$ Tris $\mathrm{HCl}$, $150 \mathrm{mM} \mathrm{NaCl}, 0.05 \%$ Tween 20) for $1 \mathrm{~h}$. The primary antibodies for phospho-ERK1/2, phosphoNFkB-p65, phospho-SAPK/JNK, phospho-p38, phospho-cAMP response element binding protein (CREB) (Cell Signaling Technology, USA), phosphor-c-Jun, and $\beta$-actin HRP (USA) were diluted in TBS-T $(20 \mathrm{mM}$ Tris $\mathrm{HCl}$, $150 \mathrm{mM} \mathrm{NaCl}, 0.05 \%$ Tween 20) and incubated for $1 \mathrm{~h}$ at RT. Next, HRP-conjugated secondary antibodies for rabbit (Santa Cruz) were diluted in TBS-T and incubated with the membranes for $1 \mathrm{~h}$ at RT. Protein bands were detected using an enhanced chemiluminescence (ECL) reagent.

\section{Migration Assay}

Breast cancer cells (MDA-MB-231) were seeded in the upper well of a 24-well Transwell chamber ( $8 \mathrm{~mm}$ pore size), and migration was estimated after $18 \mathrm{~h}$ of incubation at $37^{\circ} \mathrm{C}$ in a $\mathrm{CO}_{2}$ incubator. MDA-MB-231 cells were treated with conditioned media $(\mathrm{CM})$ or recombinant IL-10 in 24-well plates before proceeding to the Transwell for migration assays. Migrating cells were fixed with $4 \%$ PFA and stained with $1 \%$ crystal violet before being counted using bright-field microscopy.

\section{Statistical Analysis}

All experiments were performed at least three times. Data are presented as the mean \pm SD. Statistical analysis was performed using the Prism 5.0 software (GraphPad Sofware, USA). The significance of differences was assessed using an unpaired onetailed or two-tailed Student's $t$ test. Differences were considered statistically significant when the $p$ value was $<0.05$.

\section{Results}

\section{Optimization of Anti-Inflammatory Status for In Vitro Study}

In the present study, we proposed that excessive IL-10 production leads to an anti-inflammatory response, which may cause an inflammatory disease such as cancer cell metastasis. To investigate this, the alleviation effect of pLTA against abnormal anti-inflammation was examined.
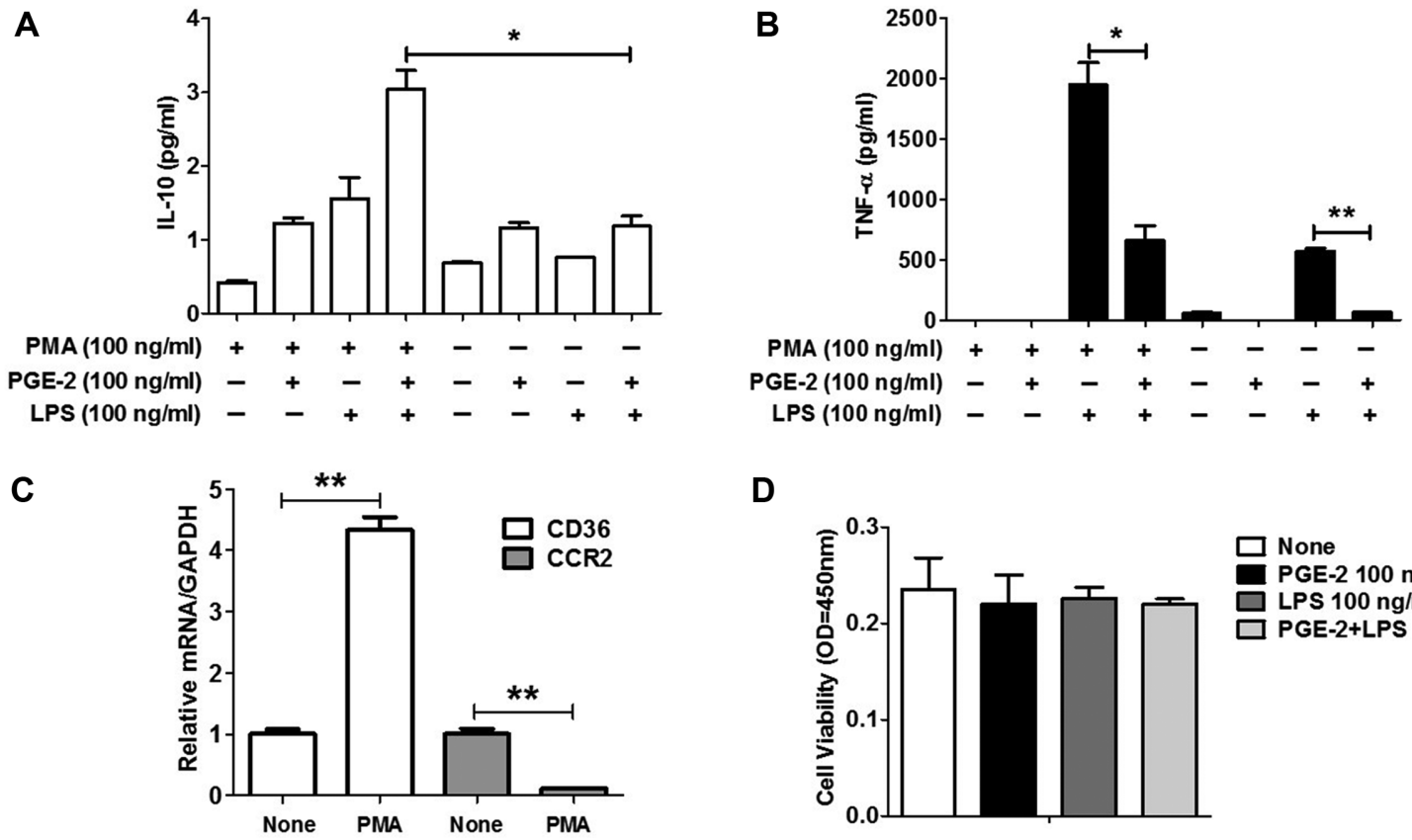

D

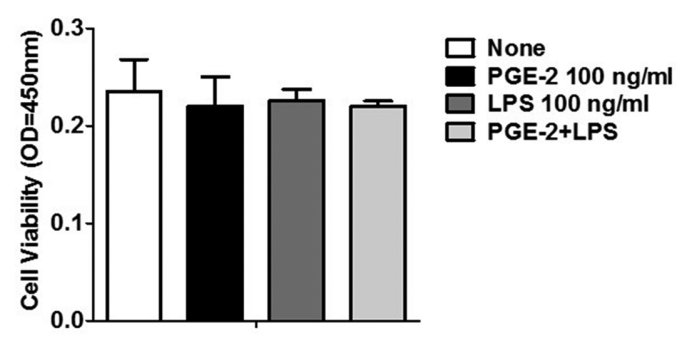

Fig. 1. Optimization of anti-inflammatory status for a study in vitro.

Phorbol-12-myristate-13-acetate (PMA)-treated or untreated THP-1 cells were stimulated with prostaglandin E2 (PGE-2) and/or lipopolysaccharide (LPS) for interleukin (IL)-10 production (A) and TNF- $\alpha$ production (B). (C) The differentiation markers were examined by realtime PCR after differentiation with PMA. (D) Cell viability was examined after treatment of PGE-2 and/or LPS for $24 \mathrm{~h}$ in PMA-differentiated THP-1 cells. ${ }^{*} p<0.05 ;{ }^{* *} p<0.01$. 
To optimize anti-inflammatory conditions in vitro, PGE-2 and/or LPS were used to stimulate THP-1 cells and PMAdifferentiated THP-1 cells. IL-10 and TNF- $\alpha$ production were examined with culture supernatants by ELISA to assume Th1/Th2 switching by these ligands. It is known that PGE-2, in combination with LPS, is able to promote an anti-inflammatory phenotype in macrophages characterized by a high level of IL-10 [13]. When PMA-differentiated THP-1 cells were treated with PGE-2 and LPS, IL-10 expression was three times higher than in untreated THP-1 cells (Fig. 1A). In PMA-differentiated THP-1 cells, IL-10 production by both PGE-2 and LPS was at least two-fold higher than when they were stimulated by each ligand alone. TNF- $\alpha$ was four-fold higher in PMA-differentiated THP-1 cells stimulated with LPS compared to THP-1 cells, whereas PGE-2 did not induce TNF- $\alpha$ expression in either cell line. Interestingly, when cells were stimulated with both PGE- 2 and LPS, TNF- $\alpha$ production was more inhibited than when cells were treated with LPS alone (Fig. 1B). These data suggest that an anti-inflammatory state (high level of IL-10 and low level of TNF- $\alpha$ ) can be induced in vitro by PGE-2 and LPS co-treatment in PMA-differentiated THP-1 cells. The differentiation of THP-1 to macrophages was confirmed by increasing CD36 and decreasing CCR2 (Fig. 1C) [14]. In addition, cell viability was not affected by the ligands used in this study (Fig. 1D).
A

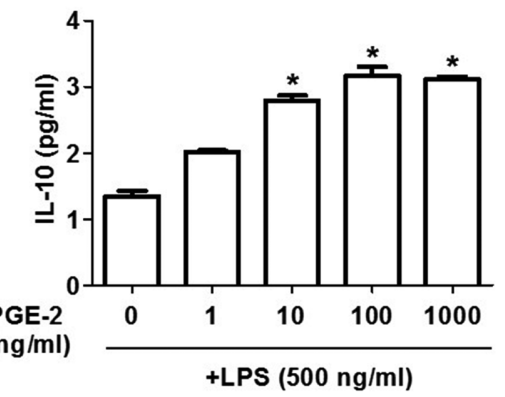

C
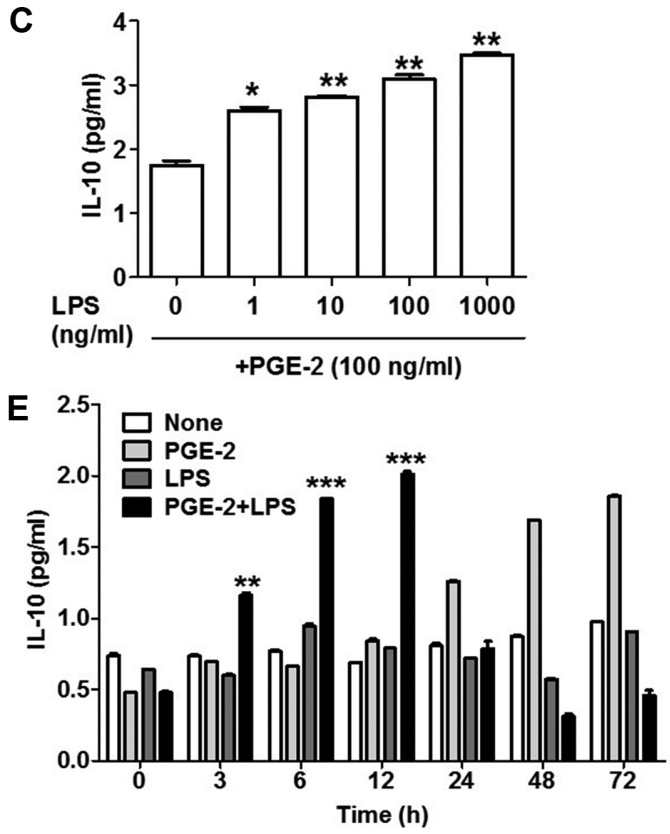

B

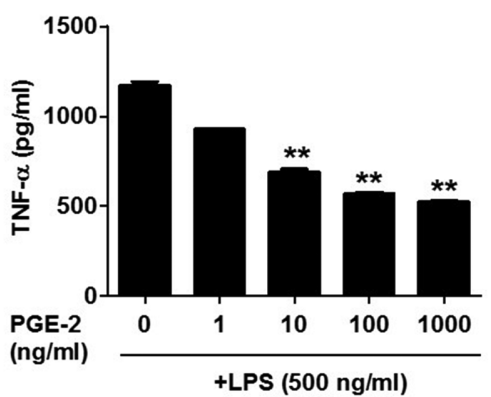

D

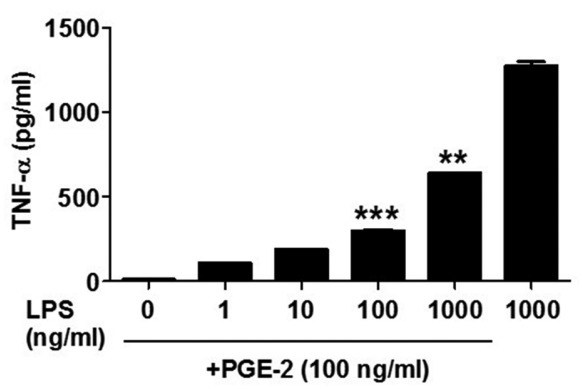

$\mathbf{F}$

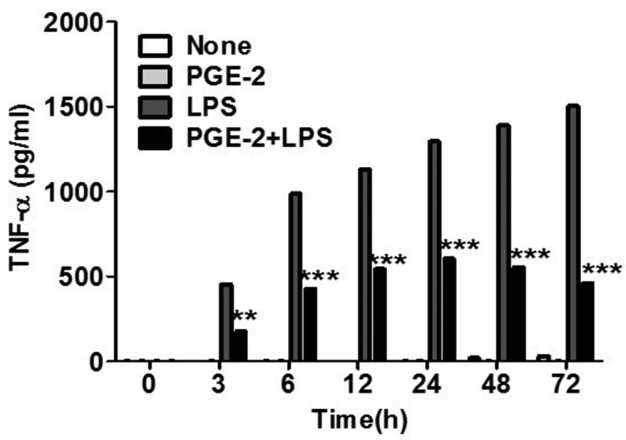

Fig. 2. Determination of prostaglandin E2 (PGE-2) and lipopolysaccharide (LPS) concentration for optical interleukin (IL)-10 and TNF- $\alpha$ production.

IL-10 (A) and TNF- $\alpha$ (B) were examined by ELISA in phorbol-12-myristate-13-acetate (PMA)-differentiated THP-1 cells stimulated with various concentrations of PGE-2 and $500 \mathrm{ng} / \mathrm{ml}$ LPS. IL-10 (C) and TNF- $\alpha$ (D) were examined in PMA-differentiated THP- 1 cells stimulated with various concentrations of LPS and $100 \mathrm{ng} / \mathrm{ml}$ PGE-2. IL-10 (E) and TNF- $\alpha$ (F) were examined in PMA-differentiated THP-1 cells stimulated with $100 \mathrm{ng} / \mathrm{ml}$ PGE-2 and LPS for the indicated time points. ${ }^{*} p<0.05 ;{ }^{* *} p<0.01 ;{ }^{* * *} p<0.001$ compared to LPS only (A and B), PGE-2 only (C and D), or $0 \mathrm{~h}(\mathbf{E}$ and F). 
Next, we determined the optimal dosages of PGE-2 and LPS to induce a high level of IL-10 and a low level of TNF$\alpha$. When PMA-differentiated THP-1 cells were stimulated with $500 \mathrm{ng} / \mathrm{ml}$ LPS and different doses of PGE-2, IL-10 production was increased in a PGE-2 dose-dependent manner (Fig. 2A). In contrast, TNF- $\alpha$ production was decreased by PGE-2 dose-dependently (Fig. 2B). When cells were stimulated with $100 \mathrm{ng} / \mathrm{ml}$ PGE-2 and different doses of LPS, IL-10 production was increased in an LPS dosedependent manner (Fig. 2C). TNF- $\alpha$ production was also increased by higher LPS dosage but was still lower than for LPS alone (Fig. 2D). These data suggest that IL-10 production is increased by the combined treatment of PGE2 and LPS, while TNF- $\alpha$ production is decreased by this combination. When cells were stimulated with $100 \mathrm{ng} / \mathrm{ml}$ PGE-2 and LPS for the indicated time points, IL-10 production peaked at $12 \mathrm{~h}$ (Fig. 2E), and TNF- $\alpha$ production in the entire period was lower than for LPS alone (Fig. 2F). Although PGE-2 only and LPS only increased IL-10 and TNF- $\alpha$ in a time-dependent manner, respectively, the experimental circumstance to meet the optimal condition for a high level of IL-10 and a low level of TNF- $\alpha$ was $6 \mathrm{~h}$ after stimulation by the combined treatment of PGE-2 and LPS.

\section{Dual Role of pLTA in IL-10 and TNF- $\alpha$ Expression}

The combined treatment of PGE-2 and LPS increased IL10 production, while it decreased TNF- $\alpha$ production in PMA-differentiated THP-1 cells. However, the opposite phenomena occurred with pLTA pretreatment. When cells were pretreated with $100 \mu \mathrm{g} / \mathrm{ml}$ pLTA for $24 \mathrm{~h}$ and then treated with PGE-2+LPS for the indicated time, IL-10 production was significantly inhibited compared to PGE2+LPS-only treated cells (Fig. 3A). On the other hand, in the same conditions, TNF- $\alpha$ production was significantly increased by pLTA pretreatment followed by PGE-2+LPS treatment (Fig. 3B). These data suggest that pLTA decreased excessive anti-inflammatory cytokine production while also establishing limited pro-inflammatory cytokine production. Next, we examined whether other LTAs have similar effects on Th1/Th2-induced cytokine production. As shown in Fig. 3C, only pLTA inhibited PGE-2+LPS-induced IL-10
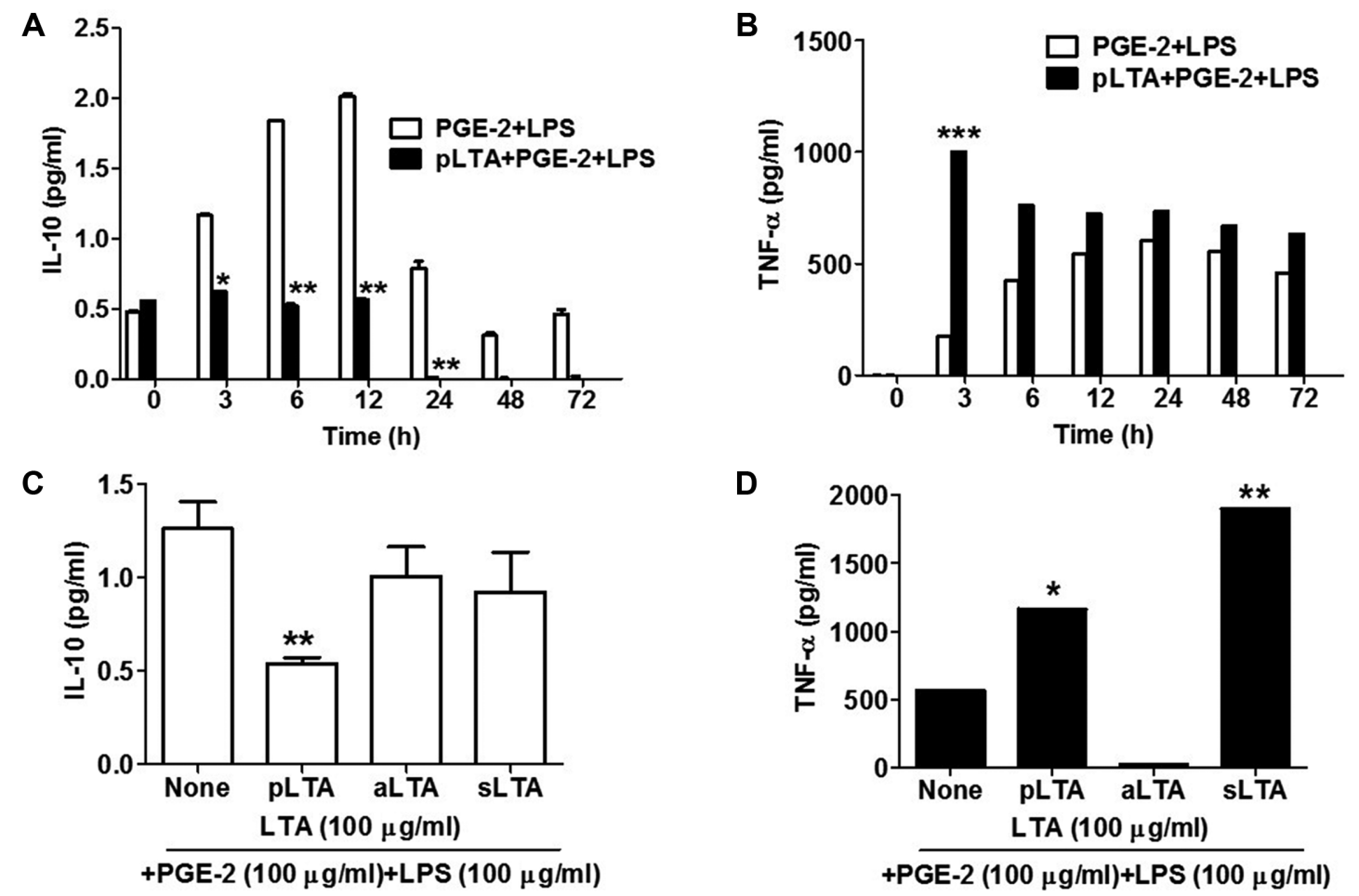

Fig. 3. Opposing regulation of interleukin (IL)-10 and TNF- $\alpha$ by pLTA.

IL-10 (A) and TNF- $\alpha$ (B) were examined in PMA-differentiated THP-1 cells stimulated with $100 \mu \mathrm{g} / \mathrm{ml}$ pLTA followed by $100 \mathrm{ng} / \mathrm{ml}$ PGE-2 and LPS for the indicated times. Inhibition of IL-10 (C) and induction of TNF- $\alpha$ (D) were examined in PMA-differentiated THP-1 cells stimulated with $100 \mu \mathrm{g} / \mathrm{ml}$ LTAs followed by $100 \mathrm{ng} / \mathrm{ml}$ PGE-2 and LPS for $12 \mathrm{~h}$ and $4 \mathrm{~h}$, respectively. ${ }^{*} p<0.05 ;{ }^{* *} p<0.01 ;{ }^{* * *} p<0.001$ compared to PGE-2+LPS (A and $\mathbf{B}$ ) or none (C and $\mathbf{D})$. 
production. However, induction of TNF- $\alpha$ occurred with pLTA as well as with LTA isolated from L. sakei (sLTA), indicating that only pLTA has a fine regulatory effect on the PGE-2+LPS-induced anti-inflammatory response (Fig. 3D).

\section{P38 and JNK Are Involved in the pLTA-Mediated Th1/ Th2 Balance}

To assess the signaling pathways for IL-10 and TNF- $\alpha$ production following treatment by PGE-2+LPS, western blotting was performed with or without pLTA pretreated cells. As shown in Fig. 4A, the phosphorylation of p38, JNK, and AP-1 was increased in PGE-2+LPS-treated cells, indicating that these mediators and transcription factor are responsible for IL-10 induction. However, the reduction of TNF- $\alpha$ seemed to be affected by inhibition of p65 and ERK. Compared to PGE-2+LPS-treated cells, the phosphorylation of p38 and p65 disappeared, and the phosphorylation of ERK, JNK, and c-Jun was increased in pLTA-pretreated cells. When cells were pretreated with pLTA followed by treatment with PGE-2 and LPS, IL-10 was inhibited and TNF- $\alpha$ production increased; thus, we assumed that decreased p38 and p65 might affect the reduction of IL-10, whereas increased JNK and c-Jun may affect the induction of TNF- $\alpha$. To confirm this hypothesis, inhibitors of signaling mediators were added $30 \mathrm{~min}$ prior to PGE-2+LPS treatment. As shown in Fig. 4B, IL-10 production was inhibited by $\mathrm{p} 38$, but the blocking of NF- $\mathrm{B}$ p 65 did not affect the reduction of IL-10, indicating that pLTAmediated IL-10 inhibition in PGE-2+LPS-treated cells is associated with p38 phosphorylation. In TNF- $\alpha$ regulation by pLTA, as we expected, a JNK inhibitor decreased TNF- $\alpha$ production, indicating that pLTA-mediated TNF- $\alpha$ induction in PGE-2+LPS conditions is associated with JNK phosphorylation (Fig. 4C).

Inhibition of Breast Cancer Cell Metastasis by pLTAMediated IL-10 Inhibition

To examine the physiological effect of pLTA-mediated IL-10 inhibition, we performed a migration assay using MDA-MB-231 cells. Migration of MDA-MD-231 cells in a Transwell chamber was dramatically increased by IL-10 and CM prepared from PMA-differentiated THP-1 cells after stimulation with PGE-2 and LPS for $24 \mathrm{~h}$. As shown in Fig. 5A, increased migrated cells were observed in IL-10 and CM treated samples as compared to untreated cells (designated as None). On the other hand, pLTA pretreatment inhibited the cell migration as compared to pLTAuntreated cells, although migrated cell population was higher than untreated cells. In particular, anti-IL-10R antibody treatment inhibited cell migration, indicating that metastasis of breast cancer cells can occur by an IL-10. The approximate number of migrated cells was counted using ImageJ software and is displayed in Fig. 5B for IL-10mediated migration, Fig. 5C for CM-mediated migration, and Fig. 5D for the inhibitory effect of anti-IL-10R antibody. Similar to the image results, the migration of pLTA-untreated cells were dramatically increased and it was significantly inhibited by pLTA-treated cells in all experiments. Even though IL-10 is not a unique material to induce breast cancer cell metastasis, our data suggest that
A

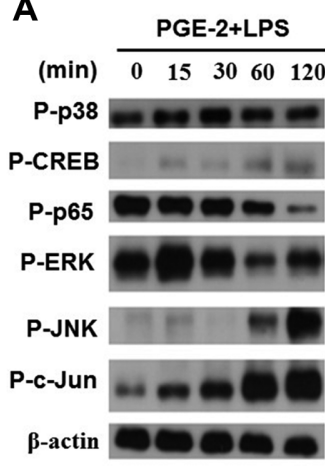

B

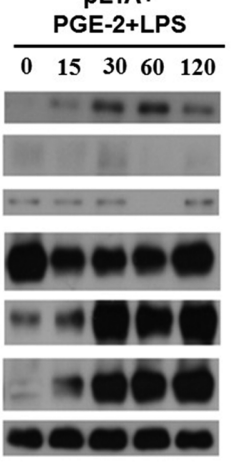

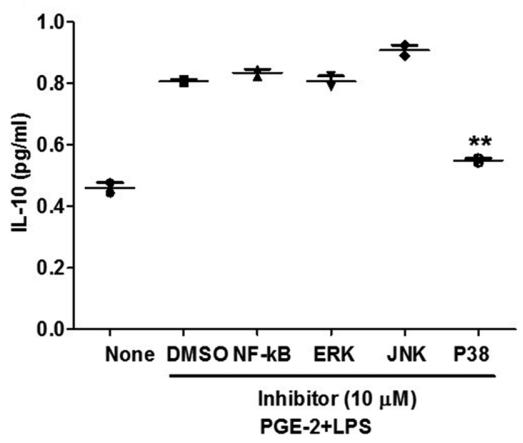

C

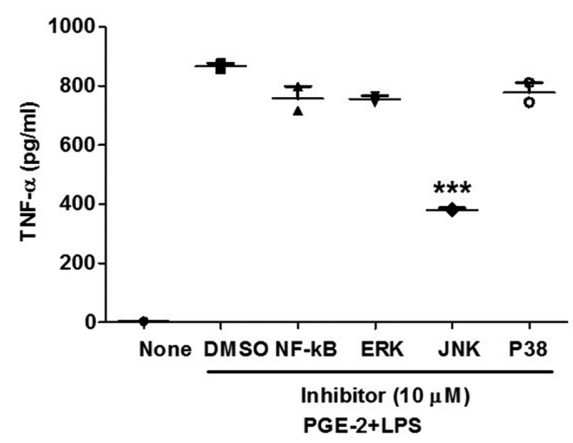

Fig. 4. Lipoteichoic acid isolated from Lactobacillus plantarum K8 (pLTA)-mediated signaling for diverse production of interleukin (IL)-10 and TNF- $\alpha$ in prostaglandin E2 (PGE-2) and lipopolysaccharide (LPS)-treated cells.

(A) Phorbol-12-myristate-13-acetate (PMA)-differentiated THP-1 cells were pretreated with or without $100 \mu \mathrm{g} / \mathrm{ml} \mathrm{pLTA}$ for $24 \mathrm{~h}$, and then $100 \mathrm{ng} / \mathrm{ml}$ PGE-2 and LPS were applied for the indicated times. Signaling activation was examined by western blotting. Cells were pretreated with indicated inhibitors for $30 \mathrm{~min}$ prior to PGE-2+LPS treatment. IL-10 (C) and TNF- $\alpha$ (B) were examined by ELISA from culture supernatants after $12 \mathrm{~h}$ and $4 \mathrm{~h}$ stimulation, respectively. ${ }^{* *} p<0.01 ;{ }^{* * *} p<0.001$ compared to DMSO. 
A
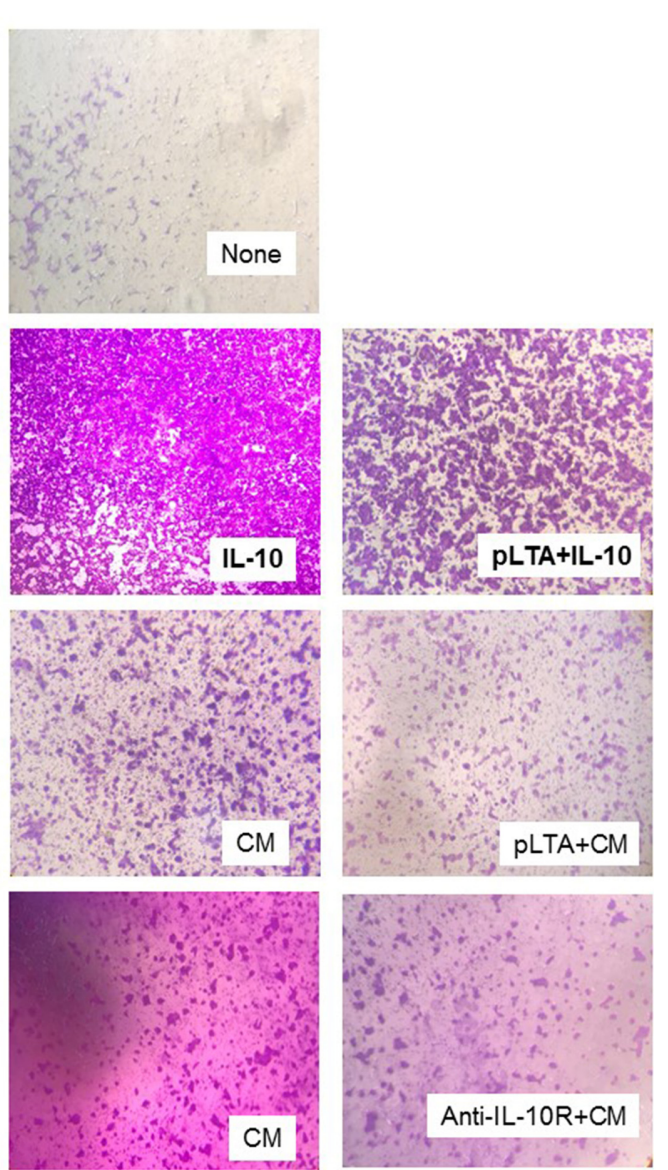

B

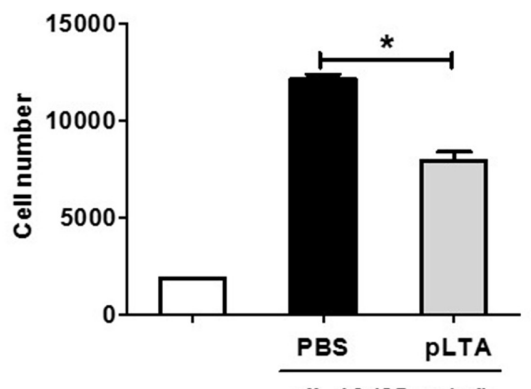

C

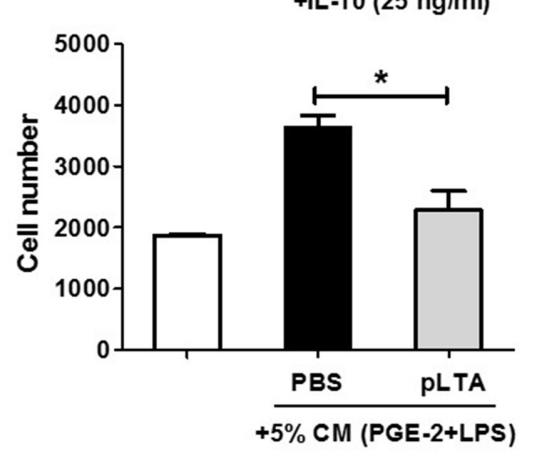

D

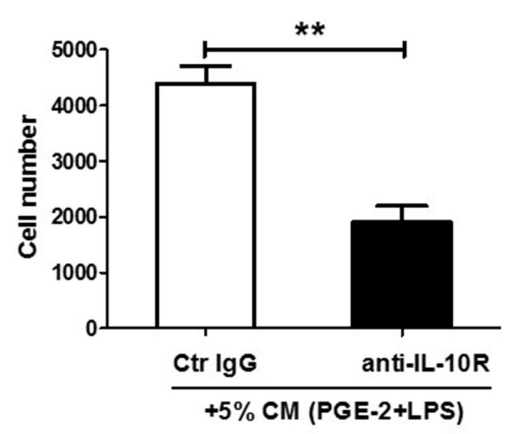

Fig. 5. Alleviation of interleukin (IL)-10-mediated metastasis by lipoteichoic acid isolated from Lactobacillus plantarum K8 (pLTA). (A) Crystal violet-stained MDA-MB-231 cells from Transwell assays. The migrated cell number was counted in IL-10-treated cells (B), cells treated with $5 \%$ conditioned media (CM) (C), and anti-IL10R antibody-treated cells (D). ${ }^{*} p<0.05 ;{ }^{* *} p<0.01$.

IL-10 may be involved in breast cancer cell metastasis and this metastasis can be alleviated by pLTA.

\section{Discussion}

Anti-inflammation refers to the effects of any materials and methods to reduce inflammation. In the immune system, reduction of inflammation is mediated by antiinflammatory cytokines such as IL-4, IL-10, and IL-13, which control the pro-inflammatory cytokine response [15]. IL-10 induces immunosuppression and allows tumor cells to escape from immune surveillance. IL-10 has a dual proliferative and inhibitory effect against breast tumor cells, suggesting that IL-10 plays a complex role in breast cancer initiation and progression [12]. Although IL-10 is a poor prognostic marker in several cancers, its expression is relatively high in breast cancer [16]. Razmkhah et al. also reported that adipose-derived stem cells (ASC) isolated from breast cancer patients express high levels of IL-10 and TGF- $\beta 1$ compared to cells isolated from normal individuals, suggesting that IL-10 could be a key cytokine involved in breast cancer progression [17]. Thus, we attempted to create an anti-inflammatory response in vitro by inducing IL-10. In culture conditions, IL-10 production was highly induced in PMA-differentiated THP-1 cells after costimulation with PGE-2 and LPS. PMA-differentiated THP-1 cells were more sensitive to PGE-2 and LPS, and synergistic induction of IL-10 was accompanied by co-treatment with these two ligands. However, TNF- $\alpha$ was not induced by PGE-2 but highly induced by LPS. When cells were 
stimulated with these two ligands simultaneously, TNF- $\alpha$ production significantly decreased. These studies suggest that combination treatment of PGE-2 and LPS in PMAdifferentiated THP-1 cells can induce a Th2 environment by increasing IL-10 and decreasing TNF- $\alpha$ production. IL-10 may inhibit tumor growth by suppressing IL-6 expression. However, higher levels of IL-10 correlate with metastatic disease and poor prognosis [18]. In the current study, we observed that IL-10 increased MDA-MB-231 breast cancer cell migration and confirmed that pLTA inhibited IL-10mediated migration of breast cancer cells.

We have reported previously the anti-inflammatory effects of pLTA; in the present study, we found that pLTA also has an inflammatory-like effect. The cell wall components of Gram-positive bacteria are known to affect bacterial infection and immune stimulation. Among them, LTA is a major immune stimulator of Gram-positive bacteria. LTA is composed of a phosphate chain and glycolipids, but the activities with respect to immune stimulation differ among species [19, 20]. For example, LTA isolated from pathogenic bacteria such as $S$. aureus increases the production of inflammatory cytokines and induces pulmonary inflammation and circulatory failure. Conversely, LTA isolated from probiotics, such as L. plantarum, induces moderate inflammation. The speciesspecific immune-stimulatory potency of different grampositive bacteria may arise from the structural differences of LTA [21]. For example, LTAs from different species have D-alanine of various contents in the repeating units of LTA [22]. The structure of lipid anchor in LTA is also diverse in the species [23]. pLTA itself does not induce proinflammatory cytokine production in the immune cells. However, pretreatment of pLTA inhibited LPS- or aLTAinduced TNF- $\alpha$ production in THP-1 cells $[2,3]$. In the current study, we observed that pLTA pretreatment increased TNF- $\alpha$ in the cells stimulated with PGE- 2 and LPS. Although the detailed mechanism should be elucidated, we assume that the activation of JNK and AP-1 may be involved in the upregulation of TNF- $\alpha$ in the cells stimulated with a combination of pLTA, PGE-2, and LPS. As shown in Fig. 4A, under the combined treatment of pLTA, PGE-2, and LPS, the phosphorylation of JNK was increased and the transcription factor AP-1 was also activated. In contrast, pLTA significantly inhibited PGE2+LPS-mediated IL-10 production through the p38 signaling pathway. Taken together, these findings indicate that pLTA regulates IL-10 and TNF- $\alpha$ production in a certain circumstance, which may contribute to maintenance of a Th1/Th2 balance.

\section{Acknowledgment}

This work was supported by a National Research Foundation of Korea (NRF) grant funded by the Korean government (MEST) (NRF-2016R1A2B1009889).

\section{Conflict of Interest}

The authors have no financial conflicts of interest to declare.

\section{References}

1. Percy MG, Gründling A. 2014. Lipoteichoic acid synthesis and function in Gram-positive bacteria. Annu. Rev. Microbiol. 68: 81-100.

2. Kim HG, Kim NR, Gim MG, Lee JM, Lee SY, Ko MY, et al. 2008. Lipoteichoic acid isolated from Lactobacillus plantarum inhibits lipopolysaccharide-induced TNF-alpha production in THP-1 cells and endotoxin shock in mice. J. Immunol. 180: 2553-2561.

3. Kim HG, Lee SY, Kim NR, Ko MY, Lee JM, Yi TH, et al. 2008. Inhibitory effects of Lactobacillus plantarum lipoteichoic acid (LTA) on Staphylococcus aureus LTA-induced tumor necrosis factor-alpha production. J. Microbiol. Biotechnol. 18: 1191-1196.

4. Hong YF, Lee HY, Jung BJ, Jang S, Chung DK, Kim H. 2015. Lipoteichoic acid isolated from Lactobacillus plantarum downregulates UV-induced MMP-1 expression and up-regulates type I procollagen through the inhibition of reactive oxygen species generation. Mol. Immunol. 67: 248-255.

5. Kim HR, Kim H, Jung BJ, You GE, Jang S, Chung DK. 2015. Lipoteichoic acid isolated from Lactobacillus plantarum inhibits melanogenesis in B16F10 mouse melanoma cells. Mol. Cells 38: $163-170$.

6. Kim H, Jung BJ, Jeong J, Chun H, Chung DK. 2014. Lipoteichoic acid from Lactobacillus plantarum inhibits the expression of platelet-activating factor receptor induced by Staphylococcus aureus lipoteichoic acid or Escherichia coli lipopolysaccharide in human monocyte-like cells. J. Microbiol. Biotechnol. 24: 1051-1058.

7. Guo H, Callaway JB, Ting JP. 2015. Inflammasomes: mechanism of action, role in disease, and therapeutics. Nat. Med. 21: 677-687.

8. de Waal Malefyt R, Abrams J, Bennett B, Figdor CG, de Vries JE. 1991. Interleukin 10 (IL-10) inhibits cytokine synthesis by human monocytes: an autoregulatory role of IL-10 produced by monocytes. J. Exp. Med. 174: 1209-1220.

9. Caux C, Massacrier C, Vanbervliet B, Barthelemy C, Liu YJ, Banchereau J. 1994. Interleukin 10 inhibits $\mathrm{T}$ cell alloreaction induced by human dendritic cells. Int. Immunol. 6: 1177-1185. 
10. Moore KW, de Waal Malefyt R, Coffman RL, O'Garra A. 2001. Interleukin-10 and the interleukin-10 receptor. Annu. Rev. Immunol. 19: 683-765.

11. Kozłowski L, Zakrzewska I, Tokajuk P, Wojtukiewicz MZ. 2003. Concentration of interleukin-6 (IL-6), interleukin-8 (IL-8) and interleukin-10 (IL-10) in blood serum of breast cancer patients. Rocz Akad Med. Bialymst 48: 82-84.

12. Hamidullah, Changkija B, Konwar R. 2012. Role of Interleukin-10 in Breast Cancer. Breast Cancer Res. Treat 133: 11-21.

13. MacKenzie KF, Clark K, Naqvi S, McGuire VA, Nöehren G, Kristariyanto $Y$, et al. 2013. PGE(2) induces macrophage IL10 production and a regulatory-like phenotype via a protein kinase A-SIK-CRTC3 pathway. J. Immunol. 190: 565-577.

14. Hong YF, Kim H, Kim HS, Park WJ, Kim JY, Chung DK. 2016. Lactobacillus acidophilus K301 Inhibits atherogenesis via induction of 24 (S), 25-epoxycholesterol-mediated ABCA1 and ABCG1 production and cholesterol efflux in macrophages. PLoS One 11: e0154302.

15. Opal SM, DePalo VA. 2000. Anti-inflammatory cytokines. Chest 117: 1162-1172.

16. Bhattacharjee HK, Bansal VK, Nepal B, Srivastava S, Dinda AK, Misra MC. 2016. Is Interleukin 10 (IL10) Expression in Breast Cancer a Marker of Poor Prognosis? Indian J. Surg. Oncol. 7: 320-325.

17. Razmkhah M, Jaberipour M, Erfani N, Habibagahi M, Talei AR, Ghaderi A. 2011. Adipose derived stem cells (ASCs) isolated from breast cancer tissue express IL-4, IL-10 and
TGF- $\beta 1$ and upregulate expression of regulatory molecules on $\mathrm{T}$ cells: do they protect breast cancer cells from the immune response? Cell Immunol. 266: 116-122.

18. Esquivel-Velázquez $\mathrm{M}$, Ostoa-Saloma $\mathrm{P}$, Palacios-Arreola $\mathrm{M}$, Nava-Castro KE, Castro JI, Morales-Montor J. 2015. The role of cytokines in breast cancer development and progression. J. Interferon Cytokine Res. 35: 1-16.

19. Leemans JC, Vervoordeldonk MJ, Florquin S, van Kessel KP, van der Poll T. 2002. Differential role of interleukin-6 in lung inflammation induced by lipoteichoic acid and peptidoglycan from Staphylococcus aureus. Am. J. Respir. Crit. Care Med. 165: 1445-1450.

20. Jeong JH, Jang S, Jung BJ, Jang KS, Kim BG, Chung DK, et al. 2015. Differential immune-stimulatory effects of LTAs from different lactic acid bacteria via MAPK signaling pathway in RAW 264.7 cells. Immunobiology 220: 460-466.

21. Ryu YH, Baik JE, Yang JS, Kang SS, Im J, Yun $\mathrm{CH}$, et al. 2009. Differential immune-stimulatory effects of Gram-positive bacteria due to their lipoteichoic acids. Int. Immunopharmacol. 9: $127-133$.

22. Morath S, Geyer A, Hartung, T. 2001. Structure-function relationship of cytokine induction by lipoteichoic acid from staphylococcus aureus. J. Exp. Med. 193: 393-397.

23. Jang KS, Baik JE, Han SH, Chung DK, Kim BG. 2011. Multispectrometric analyses of lipoteichoic acids isolated from Lactobacillus plantarum. Biochem. Biophys. Res. Commun. 407: 823-830. 